Stereotypes and Intergroup Attitudes - 1

\title{
Stereotypes and Intergroup Attitudes
}

\author{
Thierry Devos
}

San Diego State University

This is a postprint/accepted version of the manuscript. It is now published:

Devos, T. (2014). Stereotypes and intergroup attitudes. In F.T.L. Leong, L., Comas-Diaz, G.C.N., Hall, V.C., McLoyd, \& J., Trimble (Eds.), APA handbook of multicultural psychology: Theory and research (Vol. 1, pp. 341-360). Washington, DC: American Psychological Association.

Please cite the published version. The version available on PsyArXiv is before journal proof. The published version might be slightly different.

Acknowledgments: Preparation of this chapter was supported by National Institute of Mental Health Grant R24 MH 065515. The author thanks Jeff Bryson for his valuable comments on a draft of this chapter. 
Stereotypes and Intergroup Attitudes - 2

\section{Introduction}

Increasingly, terms such as diversity, multiculturalism, cultural differences, or intercultural relations are used to describe important facets of many social environments. These terms can be sources of both aspirations and concerns. Some people express their enthusiasm for the prospect of greater inclusion, cherish the coexistence of alternative worldviews, and are optimistic regarding the possibility of mutual understanding and harmony between groups. Other individuals, less sanguine, point to the dangers of societies fragmented across multiple group lines; they are pessimistic regarding the viability of multiculturalism and would prefer a societal project founded on shared values. With various degrees of sophistication, these tensions are voiced in scholarly writings, political discourses, and daily conversations. Setting aside these debates, many observers would probably agree with the following assessment: Even when equality and tolerance are considered core values in a society, distinctions between social groups continue to shape the daily experiences of large segments of its population. Social categorizations can be based on dimensions including ethnic or national origin, religion, age, gender, sexual orientation, socio-economic status, occupation, political affiliation, or physical appearance. These divisions emerge, acquire meaning, and are grounded in specific sociohistorical circumstances. As such, their implications and significance fluctuate across time and context. Capitalizing on a rich and vivid literature, the present chapter focuses on social divisions as pervasive sources of stereotypes and attitudes coming into play in multicultural settings.

Since the seminal writings of scholars such as Lippman (1922) and Allport (1954) and the pioneering investigations conducted by Katz and Braly (1933) and Sherif, Harvey, White, Hood, and Sherif (1954), much has been learned about the processes underlying stereotypes and intergroup attitudes. For example, to account for contemporary manifestations of these 
Stereotypes and Intergroup Attitudes - 3

phenomena, researchers have developed innovative theoretical frameworks and sophisticated techniques (Gawronski \& Payne, 2010; Wittenbrink \& Schwarz, 2007), which have elucidated the role of largely automatic and non-conscious processes in their expression. As a result, we now have a better understanding of covert and subtle forms of stereotyping and intergroup biases. Today, this level of analysis is particularly relevant given the prevalent social disapproval of overt public expressions of stereotypes and prejudices. This being noted, ongoing armed conflicts between groups and virulent debates about topics such as immigration or religious freedom point to the fact that early theorizing on intergroup relations still sheds light on dynamics at play today.

The goal of the present chapter is to provide an overview of core principles accounting for stereotypes and intergroup attitudes. The scientific literature on these topics is characterized by a proliferation of "micro-theories" and competing paradigms rather than by the development of an integrative framework. Reflecting the state of the field, I will borrow from a variety of theoretical frameworks. To stress the multiple facets of stereotypes and intergroup attitudes, I have organized the chapter around several distinct levels of analysis (Doise, 1986). Each of these sections calls attention to one important type of causal factor. The first three sections focus on the role of intraindividual processes: the contributions of cognitive, motivational, and affective processes are emphasized. The remaining sections examine how intergroup contexts shape stereotypes and intergroup attitudes. In these sections, I shift the focus on the impact of group memberships, socio-structural realities, evolutionary pressures, and ideological perspectives as determinants of cognitive and affective responses to social groups.

In this chapter, stereotypes are defined simply as beliefs about the attributes of a group of people (Ashmore \& Del Boca, 1981). This definition does not assume that stereotypes are 
necessarily either accurate or inaccurate (Jussim, Cain, Crawford, Harber, \& Cohen, 2009). The emphasis is on cognitive structures that contain the perceiver's knowledge, beliefs, and expectancies about particular social groups (Hamilton \& Trolier, 1986). The construct of intergroup attitudes reflects evaluative or affective distinctions between groups. Here, I center on the fact that groups might be differentially evaluated on a good-bad dimension or might elicit affective responses that vary in terms of valence (positive or negative). The term "ingroup bias" refers to the tendency to evaluate an ingroup more favorably than an outgroup (Hewstone, Rubin, \& Willis, 2002).

\section{Cognitive Underpinnings of Stereotyping}

To make sense of their social environment, perceivers often rely on cognitive processes that may result in stereotyping and intergroup biases. In this section, I examine some of these cognitive processes.

\section{Social Categorization}

Perceptions of other people are often influenced by the social categories and groups that targets belong to (Macrae \& Bodenhausen, 2000). Social categorization is a key cognitive tool for organizing social perception in an efficient and meaningful manner. It produces generalizations about ingroups and outgroups that accentuate the perceived differences between groups (contrast effect) and the perceived similarities within groups (assimilation effect, Tajfel, 1981). For example, categorizing people based on ethnicity may increase the perceived differences between ethnic groups making up the majority of the U.S. population (e.g., Asian Americans, Latino Americans, African Americans, and European Americans) and draw attention to the perceived similarities within each of these ethnic categories. Categorical thinking operates 
Stereotypes and Intergroup Attitudes - 5

at a relatively automatic level, meaning that it does not involve conscious intention, awareness, or control. People spontaneously and effortlessly categorize others based on dimensions that are considered important within their particular social context, such as race, sex, and age (Brewer \& Feinstein, 1999; Fiske, Lin, \& Neuberg, 1999). This being said, stereotypes and intergroup biases are not inevitable outcomes of cognitive processes involved in person perception. In contrast to early assumptions in the field (Devine, 1989), passively exposing perceivers to a face or asking them to make a superficial perceptual judgment is not sufficient to active stereotypes (Quinn \& Macrae, 2005). At a minimum, it is necessary to process group members in a socially meaningful manner (Macrae, Bodenhausen, Milne, Thorn, \& Castelli, 1997; Wheeler \& Fiske, 2005).

Research on social categorization has important implications for anyone interested in issues related to multiculturalism and diversity. The increasing complexity of racial identities has lead researchers to investigate how perceivers categorize multiracial individuals. Racially ambiguous persons tend to be automatically categorized as either Black or White in the absence of any information about parentage, but when the persons are characterized as having one Black parent and one White parent, they are more likely to be categorized as Black and not White (Peery \& Bodenhausen, 2008). This finding illustrates that racial categorizations reflect a legacy of rigid notions of racial identity that are not consistent with a society increasing in diversity and complexity.

More broadly, the literature reviewed in this section suggests that despite the multiple dimensions that can potentially be used to cognitively structure the social environment, individuals are prone to rely on fairly simple distinctions, precisely to reduce that complexity. In other words, the increasing diversity or complexity of many settings does not guarantee that it will be reflected in perceptions and attitudes. 
Stereotypes and Intergroup Attitudes - 6

\section{Cognitive Resources}

The cognitive resources employed in person perception have their limits. Increasing cognitive demands may moderate processes that lead to stereotyping, but the impact of cognitive load differs depending on whether stereotype activation or stereotype application is being examined. These terms distinguish two important steps of stereotyping: stereotype activation refers to the fact that a knowledge structure comes to mind and becomes readily accessible, whereas stereotype application is a subsequent step (that may or may not occur) and consists in applying the activated knowledge structure on a target. Under high cognitive load, perceivers are sometimes less likely to activate stereotypes (Gilbert \& Hixon, 1991), selectively activate the stereotype that is currently relevant (Quinn \& Macrae, 2005), or activate the stereotype that is more readily accessible (Castelli, Macrae, Zogmaister, \& Arcuri, 2004). At the later stage of stereotype application, perceivers under high cognitive load typically produce more stereotypical judgments (Bodenhausen \& Wyer, 1985; van Knippenberg, Dijksterhuis, \& Vermeulen, 1999). Given that interracial interactions have been shown to deplete cognitive resources and to impair cognitive functioning (Richeson \& Trawalter, 2005), it may be important to consider their role in stereotyping and the development of intergroup attitudes.

\section{Characteristics of the Targets}

Stereotypes are not applied uniformly across groups or individuals. That is, groups and individuals may differ in the extent to which they are likely to be processed via stereotypes or construed through the lenses of stereotypes. More precisely, characteristics of target groups and individuals strongly moderate processes underlying stereotyping. For example, individuals are more prone to depict in a stereotypical manner outgroups than ingroups; although there are several boundary conditions and exceptions to this outgroup homogeneity effect (Devos, Comby, 
\& Deschamps, 1996). The construct of perceived entitativity, the extent to which group members are seen as being bound together in a coherent unit, provides a parsimonious account of the relations between a set of group properties (e.g., similarity, interdependence, interaction) and stereotyping (Hamilton, Sherman, Crump, \& Spencer-Rodgers, 2009). Perception of entitativity not only plays a role in the emergence of stereotypical beliefs, it is also a powerful determinant of the extent to which stereotypes are applied to group members (Crawford, Sherman, \& Hamilton, 2002; Spencer-Rodgers, Hamilton, \& Sherman, 2007). When a group is viewed as highly entitative (e.g., gang members or high school clique), its members are more likely to be judged based on stereotypical expectancies.

Characteristics of individual exemplars have been shown to determine the automatic activation of stereotypes and attitudes. For example, people with more Afrocentric facial features are more likely to be stereotyped than people with less Afrocentric characteristics (Blair, Judd, Sadler, \& Jenkins, 2002; Livingston \& Brewer, 2002; Maddox \& Dukes, 2008). In the same vein, social or professional roles associated with the targets moderate automatic evaluative response to them. Given the specific ethnic stereotypes associated with Asian Americans and African Americans, evaluative distinctions between these groups will be in opposite directions whether group members are displayed in a school or basketball setting (Barden, Maddux, Petty, $\&$ Brewer, 2004). Thus, even automatically activated stereotypes are determined, in part, by the parameters of the social context.

\section{Perpetuation of Stereotypical Beliefs}

Various lines of research document that stereotypical beliefs and intergroup biases are slow to change and prone to perpetuate themselves. Perceivers can rely on an arsenal of cognitive strategies that allow them to maintain preconceived beliefs and attitudes even in the 
Stereotypes and Intergroup Attitudes - 8

face of disconfirming information. By describing behaviors that confirm expectations in a more abstract manner ("This person is aggressive") and behaviors that disconfirm expectations in a more concrete way ("This person hits a coworker"), individuals contribute to perpetuating these preconceived ideas (Wigboldus \& Douglas, 2007; Wigboldus, Semin, \& Spears, 2000). Perceivers also tend to seek evidence that confirms rather than disconfirms their stereotypes and, when behaviors confirm their stereotypical expectations, they are more likely to make dispositional inferences based on them (Trope \& Liberman, 1996; Trope \& Thompson, 1997). If people notice and remember mostly stereotype-consistent information, stereotypes grow even stronger. Under some circumstances, inconsistent information may grab perceivers' attention, in particular because this information stands out, but the outcome of this scrutiny is often an attempt to explain away or reconcile the discrepancy. For example, a successful minority candidate might be viewed as having benefited from special favors, thus his or her success has little impact on general beliefs about his or her group. To defend their stereotypes, people can also employ subtyping (Richards \& Hewstone, 2001). Forming a subtype of "Black businessman" allows people with negative stereotypes about African Americans to maintain a more general belief about the intellectual capabilities of African Americans. Finally, research on self-fulfilling processes demonstrates that stereotypical expectations may cause one to interact with a member of a stereotyped group in a way that eventually leads that person to display behaviors confirming the initial stereotypical expectations (Klein \& Snyder, 2003).

In sum, these processes allow people to maintain their preconceived beliefs and attitudes, and as a result strengthen them. The implication for issues related to multiculturalism and diversity is that changing or revising generalizations about social groups is not a minor challenge. Exposure to a diverse environment or to individuals who defy preconceived ideas is 
Stereotypes and Intergroup Attitudes - 9

not enough to dissipate stereotypical beliefs. In essence, this work points to potential obstacles to mutual understanding and challenges naïve approaches to multiculturalism.

\section{Motivational Dynamics}

A range of motivations or goals has been shown to influence stereotyping and intergroup biases (Yzerbyt, 2010). Motivational processes encompass an array of responses from relatively transient goals to more chronic or enduring needs. These motivational forces sometimes operate in a fairly overt and deliberative manner, but they can also trigger more diffuse, automatic, or unconscious responses.

\section{Understanding}

A basic assumption of research stemming from the social cognition tradition is that people process information to understand their social environment. More often than not this motive fosters stereotypical thinking. Direct evidence for this assertion can be found in research showing that the needs for closure and structure are conducive of quick and well-defined answers that stereotypes often meet given that they correspond to readily available and clearly defined beliefs (Jamieson \& Zanna, 1989; Kruglanski \& Webster, 1996). In other words, stereotypes allow people to feel like they understand specific situations or behaviors because these beliefs provide a priori structures that have no loose ends and offer psychologically pleasing explanations. However, under some circumstances, the need to understand may prompt more systematic processes. When people are motivated to be accurate, they rely less on stereotypical expectations and more on individuating information (Neuberg \& Fiske, 1987; Weary, Jacobson, Edwards, \& Tobin, 2001). Thus, at least in some cases, the fear of invalidity can undermine the propensity to rely on stereotypical knowledge in impression formation. For example, members of 
a hiring committee who are made accountable for their decisions might be less prone to rely on mental shortcuts (e.g., stereotypical expectations and beliefs) and more inclined to take into account tangible evidence of competence than individuals who have little time, incentive, or interest in selecting the best candidate for the position.

\section{Controlling}

People are also motivated to control important outcomes in their lives, including interactions with individuals they depend on. This motivation can be conceptualized broadly as a need that people have to feel like they are able to control their environment. The role that this motivation plays in stereotypical thinking is often discussed as it relates to the relative power that perceivers and targets hold in a particular context. In general, people who are in a position of power are more likely to stereotype people who are relatively powerless rather than the reverse (Fiske, 1993). When people control the outcomes of others they are more inclined to resort to stereotypical judgments, whereas when people depend on others they are more likely to seek out individuating information (Fiske \& Dépret, 1996; Goodwin, Gubin, Fiske, \& Yzerbyt, 2000). In a nutshell, power holders can afford to express or act on their stereotypes with relative impunity and they may do so, among other things, to control subordinates. In contrast, the need for control may reduce the reliance on stereotypes among low power individuals as they attempt to better understand the actions of those above them. That being said, the relation between power and stereotyping is relatively complex. Whether power fosters stereotypical judgments or produces more individuating impressions is a function of factors such as prejudice level (Vescio, Gervais, Heidenreich, \& Snyder, 2006), relationship orientation (e.g., communal vs. exchange, Chen, LeeChai, \& Bargh, 2001), and task demands (e.g., focus on responsibilities vs. relational concerns, Overbeck \& Park, 2001). 


\section{Belonging}

Affiliation needs are potent sources of influence on the extent to which people express beliefs and attitudes. The drive to belong and to get along with close others, including ingroup members, leads individuals to adopt beliefs and attitudes that correspond to group norms. People endorse stereotypical views shared within their group (Haslam et al., 1996; Sechrist \& Stangor, 2001), and will express or censor stereotypes and intergroup biases to align themselves with normative standards (Blanchard, Crandall, Brigham, \& Vaughn, 1994). Depending on their nature and content, prevalent norms may increase or decrease stereotyping and intergroup biases (Fiske \& von Hendy, 1992). In other words, stereotypes and intergroup attitudes are sensitive to the demands of interpersonal interactions and group influences.

\section{Self-Enhancing}

A pervasive motivational force is the need to preserve a positive self-image. Selfenhancement has been linked to a variety of reactions in the realm of stereotyping and intergroup biases. The picture emerging from this body of work is that stereotypes enhance self-image and threats to one's self-image increase stereotyping and outgroup derogation. In other words, these reactions can be conceptualized as defensive responses aimed at maintaining or restoring a favorable self-image. For example, to defend the self, individuals may project their own negative traits onto outgroups (Govorun, Fuegen, \& Payne, 2006). Threats to the self increase stereotype activation even under conditions known to reduce its likelihood (Spencer, Fein, Wolfe, Fong, \& Dunn, 1998). A threat to the self can not only produce stereotype activation, it can also lead to stereotype inhibition as appropriate to self-protection: After receiving negative feedback delivered by a Black doctor, individuals are likely to activate the "Black stereotype" and to 
inhibit the "Doctor stereotype" to facilitate their ability to dismiss that criticism (Sinclair \& Kunda, 1999).

These core motivational forces come into play in many daily life situations. Intergroup distinctions that are otherwise not very salient may come to the forefront and increase stereotyping when specific needs (e.g., understanding, controlling, belonging, or self-enhancing) are not met. Under some conditions, when motivation is linked to an inclination to process information more systematically, or when strong norms against the expression of stereotypical thoughts are activated, the outcome of motivational dynamics might be the expression of less stereotypical responses.

\section{The Role of Affect and Emotion}

Although the role of affect and emotions was somewhat neglected as the social cognition perspective emerged, the last couple of decades have been marked by a renewed interest in these components (Mackie \& Hamilton, 1993; Mackie \& Smith, 2002). In this section, I discuss a few important ways in which affective responses are linked to stereotyping and intergroup biases.

\section{Incidental Affect}

The importance of affective processes in stereotyping has been firmly established. Even affective or mood states that are completely or partially dissociated from the context in which stereotyping occurs (i.e., incidental affect) can influence how people process information and

form judgments. Research on the impact of incidental affect typically examines how affective states induced by watching a video clip or recalling past experiences can subsequently determine the extent to which people engage in stereotyping in subsequent, unrelated task. This approach has documented that many cognitive processes relevant to stereotyping are influenced by 
affective states. Intuitively, one might expect that negative affective states promote greater use of stereotypes, while positive affective states should have the opposite effect. Contemporary research on this issue does not support this straightforward prediction, but rather suggests that affect, mood, and emotions are sources of counterintuitive and complex effects on stereotyping (Bodenhausen, Mussweiler, Gabriel, \& Moreno, 2001). For example, in contrast to commonsense intuitions, positive affect reduces the extent to which people perceive variability within groups and increases the extent to which they rely on stereotypes (Stroessner \& Mackie, 1992). In the same vein, happiness has been shown to increase reliance on readily available stereotypes (Bodenhausen, Kramer, \& Süsser, 1994).

At least two alternative principles can account for the impact of positive affective states on stereotyping (Mackie, Queller, Stroessner, \& Hamilton, 1996). A strictly cognitive account would posit that affective states consume part of people's cognitive resources and thus limit their ability to process information systematically, increasing the likelihood that they will rely on mental shortcuts such as stereotypical beliefs. According to a more motivational account, when people experience a positive affective states, they should not be very motivated to process information given that everything seems to be fine in their immediate environment, whereas negative mood states would prompt more systematic processes aimed at understanding what needs to be addressed or at restoring a more positive affective states (Schwarz \& Clore, 2003).

\section{Specific Negative Emotions}

More recently, researchers have documented that specific negative emotions have differential effects on stereotype activation and usage. For instance, anger increases reliance on stereotypes, whereas sadness produces a more detailed and systematic processing of the available information, thus reducing stereotypical judgments (Bodenhausen, Sheppard, \& Kramer, 1994). 
In the same vein, induced anger (but not sadness) increases implicit outgroup derogation in a minimal intergroup context (DeSteno, Dasgupta, Bartlett, \& Cajdric, 2004). To account for the fact that distinct negative emotions have different and sometimes opposite effects on stereotyping, it is necessary to take into consideration the cognitive appraisals associated with these emotions. For example, experiences of anger tend to go hand in hand with the idea that someone else is responsible, whereas fear is typically associated with an appraisal of uncertainty. Thus, anger may prompt processes contributing to assigning blame or responsibility, whereas feelings of uncertainty produced by sadness may motivate people to process information more systematically (Lerner \& Keltner, 2000).

Affect, mood, and emotions should not exclusively be examined as extraneous sources of influences on stereotyping. It has long been recognized that physical or symbolic interactions with outgroup members are often accompanied by a range of discrete emotional responses (Dijker, Koomen, van den Heuvel, \& Frijda, 1996). At least under some circumstances, episodic emotional reactions that are integral aspects of the intergroup context may influence the extent to which people stereotype outgroup members (Bodehnausen et al., 2001). The reciprocal causal pathway between stereotypes and emotions may also hold. For example, specific emotional experiences, in particular anxiety, might be caused by preconceived ideas about the characteristics or beliefs of outgroup members (Finchilescu, 2010; Stephan \& Stephan, 1985).

Work reviewed in this section has important implications for multicultural settings. Indeed, interactions between members of diverse cultural groups are often characterized by both positive and negative emotions that can play a role in a complex sequence of processes and, at least under some circumstances, increase misconceptions and antipathies. Interactions with 
outgroup members may arouse both positive and negative emotions that could augment the tendency to rely on stereotypical knowledge or prompt a relatively antagonistic orientation.

\section{The Ubiquity of Ethnocentrism}

Perceived differences between groups are determined by the perceiver's vantage point. In general, group members construct stereotypes and attitudes that can be characterized as ethnocentric in that they depict the ingroup in a more positive light than outgroups. This ingroup favoritism, or ethnocentrism, is one of the most reliable and robust effects in the socialpsychological literature (Brewer, 1999; Mullen, Brown, \& Smith, 1992).

\section{Manifestations of Ethnocentrism}

Ethnocentric perceptions and attitudes take various forms. Group members not only evaluate ingroup members more positively than outgroup members, they also tend to allocate more resources or power to ingroup than outgroup members. Ingroup favoritism shapes perceptions of intergroup conflicts (Vallone, Ross, \& Lepper, 1985) and explanations for incidents or tragic events (Pratto \& Glasford, 2008). Implicit measures of attitudes also manifest consistent ingroup favoritism (Dasgupta, 2004; Devos \& Banaji, 2003). Groups unconsciously or automatically trigger more positive affective reactions when they are associated with the self, whether the ingroup-outgroup distinctions is based on ethnicity, race, national origin, or religion to name a few. For instance, both Japanese American and Korean American college students display a more positive implicit attitude toward their own ethnic group, particularly when they are strongly immersed in their own Asian culture (Greenwald, McGhee, \& Schwartz, 1998). In

all these cases, group members tend to perceive the groups or the situation in a way that depicts a favorable reality for the ingroup. 
Furthermore, ethnocentrism drives responses that are less directly evaluative in nature. Recently, the term "infra-humanization" was coined to describe the fact that individuals ascribe greater humanity to ingroups than to outgroups. For example, uniquely human emotions (e.g., love, sorrow) are automatically more linked with ingroups than with outgroups (Boccato, Cortes, Demoulin, \& Leyens, 2007), and the concept of "mankind" is more readily associated with names typical of an ingroup than of an outgroup (Boccato, Capozza, Falvo, \& Durante, 2008). In addition, reminding White Americans of violence perpetrated against Native Americans intensified the extent to which they infra-humanized Native Americans (Castano \& GinerSorolla, 2006). Finally, characteristics that differentiate the ingroup from the outgroup are seen as more uniquely human (Paladino \& Vaes, 2009).

This latter finding might reflect a general tendency to project ingroup characteristics onto a superordinate category. Issues of multiculturalism and diversity have often been conceptualized as involving more or less inclusive categorizations. Pluralistic societies and contexts are characterized by the coexistence of identifiable subgroups within a larger superordinate entity. The ingroup projection model (Mummendey \& Wenzel, 1999) emphasizes the role of ingroup and outgroup perceptions in explaining the relative exclusion of certain groups from a superordinate identity. Research based on this model documents that individuals tend to define the superordinate identity in terms of ingroup characteristics or attributes, thus creating a prototype of the superordinate identity based on these generalized ingroup attributes (Wenzel, Mummendey, \& Waldzus, 2007). For example, German citizens may consider that characteristics typically associated with their nationality are defining the prototypical European, whereas French citizens would define the prototype of a European in a way that matches defining features of their national identity. In other words, each group claims to be prototypical 
of the superordinate category. When outgroup members are evaluated based on this prototype, they tend to be seen as not matching the superordinate identity as well as ingroup members. In other words, outgroup members are not only seen as different from ingroup members, they are also viewed as not being aligned with these ethnocentric normative standards that are imposed on everyone.

\section{Minimal Basis for Ingroup Favoritism}

It has been well established that the emergence of ingroup favoritism does not presuppose or require previous hostility, face-to-face interaction, economic self-interest, or extensive knowledge about intergroup distinctions. Research based on the minimal group paradigm demonstrates that the mere categorization of individuals into two distinct groups elicits a preference for the ingroup (Diehl, 1990; Tajfel, Billig, Bundy, \& Flament, 1971). There is now evidence that a minimal social categorization is sufficient to automatically or unconsciously activate positive attitudes toward self-related groups and negative or neutral attitudes toward non-self-related groups (Otten \& Moskowitz, 2000). This means that even under relatively harmonious circumstances, divisions between groups will be sources of preferences for individuals or objects associated with the ingroup rather than outgroups.

Research on the development of implicit intergroup attitudes has shown that preferences for ingroups emerge early on and are not necessarily the result of extensive first hand experiences (Dunham, Baron, \& Banaji, 2008). A cross-sectional study of European American children revealed that 6-year-olds, 10-year-olds, and adults displayed equally strong implicit proWhite/anti-Black attitudes (Baron \& Banaji, 2006). Similarly, White British children ages 6 to 16 displayed equally strong implicit pro-White/anti-Black attitudes (Rutland, Cameron, Milne, \& McGeorge, 2005). There is also evidence that children's attitudes are influenced by significant 
adults. For example, a study conducted in Italy showed that mothers' implicit racial attitudes predicted their children's playmate preferences and attributions of negative and positive traits to a Black child (Castelli, Zogmaister, \& Tomelleri, 2009). As a whole, this work suggests that the seeds of ingroup favoritism easily take root in the sense that perceived evaluative distinctions are grounded in a learned, yet largely automatic, propensity to draw distinctions between "us" and "them."

\section{Socio-Structural Foundations of Perceived Group Differences}

Research discussed in the previous section demonstrates that perceptions of group differences are to a large extent subjective. This being said, it is important to stress that perceivers often view these perceptions as reflecting an objective reality (Leyens \& Demoulin, 2010). The fact that perceived differences between groups are driven by an ethnocentric appraisal of the world does not mean that they can be reduced to this principle. In the next section, I put the emphasis on the fact that perceived distinctions between groups are also shaped by socio-structural features of intergroup relations.

\section{Competition and Cooperation between Groups}

Classic and contemporary theories of intergroup dynamics note that intergroup images and attitudes are reflections of the nature of the relations between the groups. To the extent that groups compete for material or symbolic resources, individuals are likely to display perceptions and attitudes that map on the antagonistic nature of the relation. For example, research based on intergroup images theory shows that a behavioral orientation elicited by conflicting goals gives rise to specific images of the outgroup as the enemy (Alexander, Brewer, \& Hermann, 1999; Alexander, Brewer, \& Livingston, 2005). In contrast, cooperative interactions between groups 
drastically decrease negative attitudes. Behavioral intentions or orientations shape the content of stereotypes. These statements are not only consistent with realistic group conflict theory (Sherif et al., 1954), but also with more recent formulations of these ideas such as the unified instrumental model of group conflict (Esses, Jackson, Dovidio, \& Hodson, 2005). This more recent approach focuses less on the actual nature of the conflict or competition, but more on subjective appraisals of the intergroup context. Perceiving an outgroup as threatening ingroup resources or values is sufficient to generate stereotypical images and negative attitudes (Riek, Mania, \& Gaertner, 2006; Stephan \& Renfro, 2002). As an example, negative attitudes toward immigrants in North America are frequently grounded in the perception that they are taking away valuable resources (Esses, Dovidio, Jackson, \& Armstrong, 2001). Important societal changes (e.g., increasing diversity, new waves of immigrants) have the potential to be sources of feelings of uncertainty or threat, which are often inextricably linked to negative attitudes and hostility toward outgroups.

\section{Power and Status Asymmetries}

Relations between groups are not only conceptualized in terms of competition vs. cooperation. In many cases, what is of prime importance is the asymmetry between the groups in terms of power, social or numerical status. What is the impact of group-based hierarchies on intergroup perceptions? It has often been shown that members of subordinate groups display more ethnocentric perceptions than members of dominant groups, suggesting a stronger need to achieve a positive social identity through favorable intergroup distinctions (Judd, Park, Ryan, Brauer, \& Kraus, 1995). However, at the implicit level, members of subordinate groups are generally less likely than members of dominant groups to display a preference for their group, possibly because the social conditions impose a less favorable evaluation of the subordinate 
group (Rudman, Feinberg, \& Fairchild, 2002). For instance, in contrast to European American respondents, who show a strong implicit preference for European Americans over African Americans, African American respondents show no such consistent preference (e.g., Nosek et al., 2007). Results from laboratory data suggest that the absence of implicit ingroup favoritism among African Americans is linked to the perception that their group is held in low regard by mainstream American society (Livingston, 2002). These findings suggest that beliefs and attitudes that justify the status quo operate outside of conscious awareness or control (Jost, Banaji, \& Nosek, 2004). In contrast to a relatively conscious or deliberate effort to display ingroup liking, responses that are less conscious or controllable indicate that members of disadvantaged groups internalize the social standing of their group.

At a minimum, these findings show that ingroup favoritism can be moderated by sociostructural aspects of intergroup relations. A similar finding emerges from research examining interconnections between subgroup and superordinate identities. It is a fairly common experience for members of ethnic minorities to be seen as perpetual foreigners in their own land (Cheryan \& Monin, 2005; Huynh, Devos, \& Smalarz, 2011). The propensity to ask Asian or Latino Americans "where they are from?" may, at least in some cases, reflect the assumption that they are not American. Research employing implicit measures provide direct evidence for the idea that the concept "American" is more strongly associated with European Americans than with Asian Americans, African Americans, Latino Americans, and even Native Americans (Devos \& Banaji, 2005; Devos, Gavin, \& Quintana, 2010; Nosek, et al., 2007). Consistent with social dominance theory (Sidanius \& Pratto, 1999), the dominant group in a multiethnic society usually comes to regard itself and to be regarded by others as having ownership of the nation, its 
Stereotypes and Intergroup Attitudes - 21

resources, and its symbols. Consequently, ethnic minority status entails a certain degree of exclusion from the national identity.

Research conducted in very different contexts suggests that the tendency to perceive ingroup members as more prototypical of the superordinate category than outgroup members is stronger among majority than minority group members. Studies conducted in Germany since reunification suggest that the majority group (West Germans) is perceived by both West and East Germans as more prototypical of the superordinate German identity, but members of the majority group tend to perceive larger differences than do minority group members (Waldzus, Mummendey, Wenzel, \& Boettcher, 2004). In sum, the larger socio-cultural environment contributes to sustain the perception that the dominant group in a society embodies the superordinate identity to a greater extent than groups holding less power or status.

Research based on the stereotype content model (Fiske, Cuddy, Glick, \& Xu, 2002) nicely illustrates the link between social-structural dimensions (competition and status) and perceptions of social groups. In line with classic and contemporary research on social judgments and impression formation, the model posits that perceptions of individuals and groups are structured according to two fundamental dimensions: the warmth-morality dimension captures traits related to perceived intent, including friendliness, helpfulness, sincerity, and trustworthiness, whereas the competence-agency dimension includes traits that are related to perceived ability, including intelligence, skill, creativity, and efficacy. Together, these two dimensions of social cognition account for a large proportion of variances in stereotypical images of social groups. To illustrate the model, one can consider the four possible combinations (or quadrants) resulting from crossing these two primary dimensions. Ingroups and societal reference groups (e.g., Americans, Christians, the middle class) occupy the high-warmth, high- 
competence quadrant. At the opposite extreme (low-warmth, low-competence) are society's discards or outsiders (e.g., poor people, drug addicts, and the homeless). The remaining, mixed combinations reflect ambivalences that are more novel to consider as stereotypes. Liked but disrespected groups include the elderly and disabled, whereas disliked but respected groups include rich people, Asians, Jews, and female professionals.

This cognitive mapping of stereotypes has been replicated using a wide variety of samples and its cross-cultural validity has been documented (Cuddy et al., 2009). Relevant to the socio-structural foundations of stereotypes is the finding that status predicts perceptions of high competence, and competition predicts perception of low warmth (Fiske et al., 2002). The model also accounts for the sometimes complex images that perceivers hold about immigrant groups. If the generic immigrants tend to be depicted as incompetent and cold, a more nuanced picture emerges when more specific groups defined on the basis of nationality, race, ethnicity, or class are being considered (Lee \& Fiske, 2006). Stereotypes about many immigrant groups can be characterized as ambivalent. For example, some Asian groups (e.g., Japanese, Chinese, or Korean immigrants) are seen as competent, but not warm, whereas other groups (e.g., Irish or Italian immigrants) are seen as warm, but not competent. Here also the location of these groups in the two-dimensional space is linked to perceptions of status and competition.

Recent research based on intergroup images theory also lends support to the idea that the relative status of the groups shape intergroup images (Alexander et al., 2005): White college students hold an image of Natives as dependent, whereas college students from a Native American nation hold an imperialist and barbarian image of Whites. The case of American Indians provides striking illustrations of potent psychological mechanisms through which a numerical minority relatively deprived of material and symbolic resources is stereotyped in ways 
that contribute to its marginalization and exclusion. For example, depictions of American Indians frequently reinforce and perpetuate common misconceptions (Trimble, 1988). In textbooks, movies, and sports arenas, American Indians are depicted as "brave warriors" or "exotic others."

Despite the fact that these stereotypical images have positive connotations in some contexts, they are offensive and hurtful for American Indians. Indeed, there is clear evidence showing that exposures to American Indian mascots (e.g., Chief Wahoo, Chief Illinwek, or Pocahontas) negatively impact the self-concept of American Indian students: these stereotypical portrayals depress their self-esteem and sense of community worth, and undermine their aspirations (Fryberg, Markus, Oyserman, \& Stone, 2008). These findings point to the fact that caricatures of social groups are harmful in that they remind individuals of the simplified ways in which others view them and constrain how they can define themselves.

In sum, perceptions of social groups are not elaborated in a vacuum, but are inextricably linked to the structural features of intergroup relations. On a broader level, work reviewed in this section reminds us that material and symbolic interests are very much at play in intergroup dynamics. Issues of diversity and multiculturalism cannot be dissociated from the nature of the relations between groups and their relative standings. Diversity per se does not ensure that group members will set limits to their inclination to strive for power, resources, rights, and recognition; it may even serve to exacerbate these tendencies.

\section{Evolutionary Account of Perceived Group Differences}

Human's propensity to engage in stereotyping and to display intergroup biases can also be accounted for using an evolutionary framework. Two kinds of evolutionary processes shed light on psychological processes contributing to these phenomena (Schaller, Conway, \& Peavy, 2010). On one hand, genetic evolution explains how psychological mechanisms can be 
Stereotypes and Intergroup Attitudes - 24

selectively transmitted from individuals to their offspring through sexual reproduction. On the other hand, cultural evolution accounts for the fact that many forms of knowledge are selectively transmitted between individuals through interpersonal communication. In this section, I examine the explanatory power of these two kinds of evolutionary processes.

\section{Genetic Evolution}

In contrast to many other species, human beings are physically weak and slow to mature, limitations that impose a lifestyle characterized by obligatory interdependence (Brewer \& Caporael, 2006). Many psychological adaptations may help meet this challenge. For example, psychological mechanisms that allow individuals to differentiate ingroup members (potential allies) from outgroup members (potential enemies) are adaptive. These mechanisms help identify whom to behave altruistically toward and limit the risk of exploitation by those who are not likely to help you. From this particular vantage point, intergroup biases are best conceptualized as a form of ingroup favoritism (preference for ingroup members) rather than outgroup derogation (antipathy directed toward outgroup members) (Brewer, 1999). The evolutionary framework also accounts for the fact that different social groups are seen as representing functionally distinct threats. Different outgroups elicit distinct affective and behavioral responses, depending on whether they are seen as posing threats to one's resources, values, or physical safety (Cottrell \& Neuberg, 2005; Neuberg \& Cottrell, 2006). In addition, the evolutionary framework may help explain why cues signaling coalitional group memberships strongly affect how people categorize their environment and may be more potent than distinctions based on cues such as skin color (Cosmides, Tooby, \& Kurzban, 2003). Of course, many of these phenomena can be accounted for based alternative theoretical models or cannot be 
reduced to mechanisms of psychological adaptations. This being said, it is likely that they have some functionality from an evolutionary perspective.

\section{Cultural Evolution}

Cultural evolution helps explain how stereotypes are perpetuated in a given culture. From this perspective, stereotypes are both individual cognitive representations and culturally shared representations. The extent to which a stereotype is shared within a population is largely a function of patterns of interpersonal communication. A variety of psychological processes determine whether people will communicate specific aspects of a stereotype. Traits that are more likely to be talked about are more likely to be central to the cultural stereotype (Schaller, Conway, \& Tanchuk, 2002). The likelihood that a specific belief is communicated is a function of the goals or motives that are contextually salient. In at least some contexts, traits that denote danger or safety are more likely to be mentioned because they have important implications for one's physical well-being. This may explain why these traits tend to persist in cultural stereotypes (Schaller, Faulkner, Park, Neuberg, \& Kenrick, 2004).

\section{Impact of Intergroup Ideologies}

In this section, I examine the interconnections between intergroup ideologies and the propensity to differentiate between groups either cognitively or evaluatively, focusing in particular on the burgeoning interest in the distinction between a colorblind perspective and a multicultural perspective. Thus, I am considering the broader ideological context shaping mechanisms likely to increase or decrease perceived differences between groups. Given the theme of present volume, the discussion will be centered on two widespread belief systems regarding the optimal way to manage interactions in diverse settings. 
Stereotypes and Intergroup Attitudes - 26

\section{Colorblind Ideology}

Given the potent role that social categorization plays in intergroup biases, several lines of research have explored the possibility that diminishing category distinctions might be a promising avenue for reducing those biases. This idea is termed the colorblind approach in that it is based on the notion that harmony is best achieved by ignoring group differences and seeing everyone as individuals rather than group members. According to the decategorization model (Brewer \& Miller, 1984), reduction in intergroup conflict is best achieved when members of different groups view each other as individuals. Similarly, one assumption of influential models of impression formation is that reducing stereotype usage requires moving away from categorybased processes and allowing more individuating processes to come into play (Brewer \& Feinstein, 1999; Fiske, et al., 1999). As the earlier discussion of the role of cognitive and motivational factors stressed, the latter often requires attentional resources and specific motivational forces.

Despite the empirical evidence supporting these models, two important limitations of the colorblind approach have been noted (Park \& Judd, 2005). First, given that social categorization is a very basic and pervasive cognitive process, counteracting or eliminating categorical thinking might be a daunting task. Second, given that distinctions between groups are sources of valued social identities, downplaying these distinctions implies that individuals would have to relinquish important aspects of their self-concept. That being said, it is worth pointing out that colorblindness is a very widespread perspective that is fairly prevalent in educational and professional settings.

The challenges of a colorblind perspective are illustrated by research on stereotype suppression. In some cases, people may deliberately try to suppress stereotypical thoughts. They 
may be successful under some circumstances (Monteith, Sherman, \& Devine, 1998), but there is clear evidence that these efforts may backfire and actually increase reliance on stereotypes. The unintended and ironic consequence of stereotype suppression is that suppressing unwanted stereotypical thoughts actually increases their accessibility and makes it more likely that they will come to mind and shape responses when perceivers are unable to search for alternative responses (Macrae, Bodenhausen, Milne, \& Jetten, 1994; Wyer, Sherman, \& Stroessner, 1998). In the same vein, adopting a colorblind approach has been linked to relatively negative and inefficient patterns of communication in interracial interactions (Norton, Sommers, Apfelbaum, Pura, \& Ariely, 2006). One possible explanation is that the cognitive demands of suppressing spontaneous categorical responses lead individuals to behave in a less friendly or open manner toward members of ethnic minority groups. In other words, stereotype suppression may deplete individuals from the cognitive resources necessary to behave in line with the standard they wish to uphold (colorblindness).

\section{Multiculturalism as an Alternative Ideology}

Given the limitations of the colorblind model, there has been a recent shift toward exploring multiculturalism as an alternative route to reduce intergroup biases (Park \& Judd, 2005). Multiculturalism is based on the idea that ethnic or cultural differences should be acknowledged, even celebrated, rather than ignored or suppressed. Several models and lines of work are based on these assumptions. For instance, the mutual differentiation model argues that introducing a cooperative relationship between groups without dismantling group boundaries or identities is the most effective approach to reduce intergroup biases (Hewstone \& Brown, 1986). In a similar vein, the benefits of making salient a superordinate identity are often most evident when subgroup identities are maintained rather than overridden (Hornsey \& Hogg, 2000). 
Stereotypes and Intergroup Attitudes - 28

The viability of the multicultural approach also emerges from research showing the benefits of inducing a more complex representation of the social environment. For example, the tendency to engage in ingroup projection is strongly reduced when a more complex representation of the superordinate identity is induced (Waldzus, Mummendey, Wenzel, \& Weber, 2003). In other words, a complex superordinate identity is more inclusive than imposing a simple and homogeneous definition on all subgroups. This is consistent with research showing that intergroup biases can be significantly reduced when diverse, overlapping, and cross-cutting categorical distinctions structure the cognitive representation that individuals have of their social environment (Crisp \& Hewstone, 2007).

\section{Contrasting Colorblindness and Multiculturalism}

More recently, researchers have started to compare the impact of these two ideologies on intergroup biases. For example, priming either a colorblind or multicultural perspective has been shown to reduce intergroup biases compared to a control condition (Wolsko, Park, Judd, \& Wittenbrink, 2000). Interestingly, individuals who were encouraged to adopt a multicultural perspective perceived greater differences between ethnic groups than individuals who were led to adopt the colorblind perspective. The latter result suggests that reduction of evaluative biases does not necessarily require downplaying perceived distinctions between groups. This point is nicely illustrated by a series of studies showing that highlighting category boundaries does not increase intergroup bias (Deffenbacher, Park, Judd, \& Correll, 2009). For both minimal and natural groups, calling attention to group differences (compared to minimizing them) accentuated perceived distinctions between groups, but left evaluative intergroup biases unchanged. Emphasizing differences between groups while simultaneously focusing on the self may reduce intergroup biases (Carpenter, Zárate, \& Garza, 2007). When primed to adopt a multicultural 
perspective, individuals displayed weaker implicit pro-White attitudes than when primed to adopt the colorblind approach (Richeson \& Nussbaum, 2004). In addition, a perspective that attempts to minimize the role of race in daily situations reduced the likelihood that children noticed racial biases in a school setting and described instances of racial discrimination in a way that would prompt adult interventions, compared to a perspective that recognizes the importance of this factor and affirm the value of diversity (Apfelbaum, Pauker, Sommers, \& Ambady, 2010).

Not surprisingly, members of ethnic minorities endorse multiculturalism to a greater extent than White Americans (Ryan, Hunt, Weible, Peterson, \& Casas, 2007; Wolsko, Park, \& Judd, 2006). Ethnic minorities subscribe to an ideology that advocates the recognition of unique customs, values, and traditions instead of endorsing an ideology that renders ethnicity irrelevant. Colorblindness is often viewed as a form of bias by members of minority groups (Apfelbaum, Sommers, \& Norton, 2008; Purdie-Vaughns, Steele, Davies, Ditlmann, \& Crosby, 2008). Without a doubt, these intergroup ideologies have contrasting implications for majority and minority groups. A series of studies documents that the concept of "exclusion" is associated with multiculturalism among White American respondents, but not among respondents who belong to an ethnic minority group (Plaut, Garnett, Buffardi, \& Sanchez-Burks, 2011). As was recently pointed out, a desire to avoid cultural change or, conversely, to continue ongoing cultural change might be mediating the distinct responses to intergroup ideologies among majority and minority groups (Zárate \& Shaw, 2010). Consistent with this perspective, White Americans who strongly identify with their ethnic group display stronger intergroup biases when primed with multiculturalism, an effect stemming from a sense of threat to ingroup values (Morrison, Plaut, \& Ybarra, 2010). Work reviewed in this section suggests that the colorblind perspective might not be as effective as lay people often assume and that it might be productive to consider 
alternative approaches such as the multicultural perspective. At the same time, both approaches comes with specific challenges that are often linked to what they entail or signify for majority and minority group members.

\section{Conclusion}

As was stressed at the onset of this chapter, many contexts can be characterized by an unprecedented degree of diversity. This growing diversity is often seen as an opportunity to engender a more inclusive and tolerant perspective. To a large extent, I have examined challenges and obstacles to mutual understanding and harmony between groups. The research literature reflects the larger social reality that interactions between members of different groups are often characterized by conflicts and communication breakdowns that interfere with mutual cooperation and effective functioning.

My goal was to bring together multiple perspectives focusing on the underlying forces leading to stereotyping and intergroup biases. First, I emphasized the role of basic cognitive, motivational, and affective processes contributing to these phenomena. A fairly straightforward picture emerges from the relevant literature. Despite the fact that individuals navigate through environments that can be organized around multiple group lines, they might continue to categorize these environments according to simple dichotomous distinctions and display judgments tainted by stereotypical beliefs. In other words, increasing the complexity or diversity of a setting does not guarantee that individuals' cognitive mapping of this setting will reflect this complexity. However, this is not to argue that diversity has no effect on how individuals cognitively represent the world. As mentioned, under some circumstances the very same basic cognitive tools can be employed to produce a more multifaceted picture and reduce ingroupoutgroup evaluative distinctions. 
I also highlighted the influence that socio-structural realities have on intergroup perceptions and attitudes. In doing so, I tried to stress that attention to issues related to diversity and multiculturalism should not overshadow the fact that structural features of societies determine how people perceive, understand, and evaluate others. Holding a relatively dominant, high status, or majority position versus occupying a more subordinate, low status, or minority position constrains the extent to which group members feel included and valued. Resistance to diversity and multiculturalism on the part of majority group members are often grounded in group interests and, as a result, overcoming these resistances is not a trivial task. Societal changes have implications for the balance of power (e.g., access to resources, opportunities, rights, or political representation). Thus, they can be sources of both insecurity and hope, and these concerns or aspirations are anchored in intergroup perceptions and attitudes. The discussion of evolutionary mechanisms also points to the far-reaching roots of these phenomena. In another way, the evolutionary level of analysis stresses that the mechanisms contributing to stereotyping and intergroup biases are not necessarily affected by fluctuations in the make-up of the population or by shifts in values or ideologies. In other words, changes in societal diversity and social norms regarding how to behave in diverse settings, may meet resistances due to evolutionary-based dynamics that have relatively stable foundations. From that perspective, a superficial endorsement of multiculturalism may make it more difficult to challenge pervasive structural inequalities. In fact, reflections on this issue should be informed by a detailed analysis of how structural arrangements can preserve existing categorical distinctions.

To conclude, the literature on stereotypes and intergroup attitudes provides a useful background to any discussion on how to deal with diversity. Considering the role of basic psychological processes and core aspects of intergroup relations does not lead to clear-cut 
Stereotypes and Intergroup Attitudes - 32

conclusions (pessimistic or optimistic) regarding the impact of multiculturalism or diversity on human interactions, but it can yield a better understanding of the complexities, vicissitudes, and ramifications of dynamics coming into play in multicultural settings. The principles covered in this chapter, singly or in combination, shed light on dynamics that are not inevitable, but that are often potent forces operating in diverse environments. 
Stereotypes and Intergroup Attitudes - 33

\section{References}

Alexander, M. G., Brewer, M. B., \& Hermann, R. K. (1999). Images and affect: A functional analysis of out-group stereotypes. Journal of Personality and Social Psychology, 77(1), 78-93.

Alexander, M. G., Brewer, M. B., \& Livingston, R. W. (2005). Putting stereotype content in context: Image theory and interethnic stereotypes. Personality and Social Psychology Bulletin, 31(6), 781-794.

Allport, G. W. (1954). The nature of prejudice. Cambridge: Addison-Wesley.

Apfelbaum, E. P., Pauker, K., Sommers, S. R., \& Ambady, N. (2010). In blind pursuit of racial equality? Psychological Science, 21(11), 1587-1592.

Apfelbaum, E. P., Sommers, S. R., \& Norton, M. I. (2008). Seeing race and seeming racist? Evaluating strategic colorblindness in social interaction. Journal of Personality and Social Psychology, 95(4), 918-932.

Ashmore, R. D., \& Del Boca, F. K. (1981). Conceptual approaches to stereotypes and stereotyping. In D. L. Hamilton (Ed.), Cognitive processes in stereotyping and intergroup behavior (pp. 1-36). Hillsdale: Erlbaum.

Barden, J., Maddux, W. W., Petty, R. E., \& Brewer, M. B. (2004). Contextual moderation of racial bias: The impact of social roles on controlled and automatically activated attitudes. Journal of Personality and Social Psychology, 87(1), 5-22.

Baron, A. S., \& Banaji, M. R. (2006). The development of implicit attitudes: Evidence of race evaluations from ages 6 and 10 and adulthood. Psychological Science, 17(1), 53-58.

Blair, I. V., Judd, C. M., Sadler, M. S., \& Jenkins, C. (2002). The role of Afrocentric features in person perception: Judging by features and categories. Journal of Personality and Social Psychology, 83(1), 5-25.

Blanchard, F. A., Crandall, C. S., Brigham, J. C., \& Vaughn, L. A. (1994). Condemning and condoning racism: A social context approach to interracial settings. Journal of Applied Psychology, 79(6), 993-997.

Boccato, G., Capozza, D., Falvo, R., \& Durante, F. (2008). The missing link: Ingroup, outgroup and the human species. Social Cognition, 26(2), 224-234.

Boccato, G., Cortes, B. P., Demoulin, S., \& Leyens, J. P. (2007). The automaticity of infrahumanization. European Journal of Social Psychology, 37(5), 987-999.

Bodenhausen, G. V., Kramer, G. P., \& Süsser, K. (1994). Happiness and stereotypic thinking in social judgment. Journal of Personality and Social Psychology, 66(4), 621-632.

Bodenhausen, G. V., Mussweiler, T., Gabriel, S., \& Moreno, K. N. (2001). Affective influences on stereotyping and intergroup relations. In J. P. Forgas (Ed.), Handbook of affect and social cognition (pp. 319-343). Mahwah, NJ: Erlbaum.

Bodenhausen, G. V., Sheppard, L. A., \& Kramer, G. P. (1994). Negative affect and social judgment: The differential impact of anger and sadness. European Journal of Social Psychology, 24(1), 45-62. 
Bodenhausen, G. V., \& Wyer, R. S. (1985). Effects of stereotypes in decision making and information-processing strategies. Journal of Personality and Social Psychology, 48(2), 267-282.

Brewer, M. B. (1999). The psychology of prejudice: Ingroup love or outgroup hate? Journal of Social Issues, 55(3), 429-444.

Brewer, M. B., \& Caporael, L. R. (2006). An evolutionary perspective on social identity: Revisiting groups. In M. Schaller, J. A. Simpson \& D. T. Kenrick (Eds.), Evolution and social psychology (pp. 143-161). Madison, CT US: Psychosocial Press.

Brewer, M. B., \& Feinstein, A. S. H. (1999). Dual processes in the cognitive representation of persons and social categories. In S. Chaiken \& Y. Trope (Eds.), Dual-process theories in social psychology (pp. 255-270). New York, NY,US: Guilford Press.

Brewer, M. B., \& Miller, N. (1984). Beyond the contact hypothesis: Theoretical perspectives on desegregation. In N. Miller \& M. B. Brewer (Eds.), Groups in contact: The psychology of desegregation (pp. 281-302). Orlando: Academic Press.

Carpenter, S., Zárate, M. A., \& Garza, A. A. (2007). Cultural pluralism and prejudice reduction. Cultural Diversity and Ethnic Minority Psychology, 13(2), 83-93.

Castano, E., \& Giner-Sorolla, R. (2006). Not quite human: Infrahumanization in response to collective responsibility for intergroup killing. Journal of Personality and Social Psychology, 90(5), 804-818.

Castelli, L., Macrae, C. N., Zogmaister, C., \& Arcuri, L. (2004). A tale of two primes: Contextual limits on stereotype activation. Social Cognition, 22(2), 233-247.

Castelli, L., Zogmaister, C., \& Tomelleri, S. (2009). The transmission of racial attitudes within the family. Developmental Psychology, 45(2), 586-591.

Chen, S., Lee-Chai, A. Y., \& Bargh, J. A. (2001). Relationship orientation as a moderator of the effects of social power. Journal of Personality and Social Psychology, 80(2), 173-187.

Cheryan, S., \& Monin, B. (2005). 'Where are you really from?': Asian Americans and identity denial. Journal of Personality and Social Psychology, 89(5), 717-730.

Cosmides, L., Tooby, J., \& Kurzban, R. (2003). Perceptions of race. Trends in Cognitive Sciences, 7(4), 173-179.

Cottrell, C. A., \& Neuberg, S. L. (2005). Different emotional reactions to different groups: A sociofunctional threat-based approach to 'prejudice'. Journal of Personality and Social Psychology, 88(5), 770-789.

Crawford, M. T., Sherman, S. J., \& Hamilton, D. L. (2002). Perceived entitativity, stereotype formation, and the interchangeability of group members. Journal of Personality and Social Psychology, 83(5), 1076-1094.

Crisp, R. J., \& Hewstone, M. (2007). Multiple social categorization. Advances in Experimental Social Psychology, 39, 163-254.

Cuddy, A. J. C., Fiske, S. T., Kwan, V. S. Y., Glick, P., Demoulin, S., Leyens, J.-P, Bond, M. H., et al. (2009). Stereotype content model across cultures: Towards universal similarities and some differences. British Journal of Social Psychology, 48(Pt 1), 1-33. 
Dasgupta, N. (2004). Implicit ingroup favoritism, outgroup favoritism, and their behavioral manifestations. Social Justice Research, 17(2), 143-169.

Deffenbacher, D. M., Park, B., Judd, C. M., \& Correll, J. (2009). Category boundaries can be accentuated without increasing intergroup bias. Group Processes \& Intergroup Relations, 12(2), 175-193.

DeSteno, D., Dasgupta, N., Bartlett, M. Y., \& Cajdric, A. (2004). Prejudice from thin air: The effect of emotion on automatic intergroup attitudes. Psychological Science, 15(5), 319 324.

Devine, P. G. (1989). Stereotypes and prejudice: Their automatic and controlled components. Journal of Personality and Social Psychology, 56(1), 5-18.

Devos, T., \& Banaji, M. R. (2003). Implicit self and identity. In M. R. Leary \& J. P. Tangney (Eds.), Handbook of self and identity (pp. 153-175). New York, NY US: Guilford Press.

Devos, T., \& Banaji, M. R. (2005). American = White? Journal of Personality and Social Psychology, 88(3), 447-466.

Devos, T., Comby, L., \& Deschamps, J. C. (1996). Asymmetries in judgements of ingroup and outgroup variability. European Review of Social Psychology, 7, 95-144.

Devos, T., Gavin, K., \& Quintana, F. J. (2010). Say "adios" to the American dream? The interplay between ethnic and national identity among Latino and Caucasian Americans. Cultural Diversity and Ethnic Minority Psychology, 16(1), 37-49.

Diehl, M. (1990). The minimal group paradigm: Theoretical explanations and empirical findings. European Review of Social Psychology, 1, 263-292.

Dijker, A. J., Koomen, W., van den Heuvel, H., \& Frijda, N. H. (1996). Perceived antecedents of emotional reactions in inter-ethnic relations. British Journal of Social Psychology, 35(Pt 2), 313-329.

Doise, W. (1986). Levels of explanation in social psychology. Cambridge - Paris: Cambridge University Press - Maison des Sciences de l'Homme.

Dunham, Y., Baron, A. S., \& Banaji, M. R. (2008). The development of implicit intergroup cognition. Trends in cognitive sciences, 12(7), 248-253.

Esses, V. M., Dovidio, J. F., Jackson, L. M., \& Armstrong, T. L. (2001). The immigration dilemma: The role of perceived group competition, ethnic prejudice, and national identity. Journal of Social Issues, 57(3), 389-412.

Esses, V. M., Jackson, L. M., Dovidio, J. F., \& Hodson, G. (2005). Instrumental relations among groups: Group competition, conflict, and prejudice. In J. F. Dovidio, P. Glick \& L. A. Rudman (Eds.), On the nature of prejudice: Fifty years after Allport (pp. 227-243). Malden: Blackwell Publishing.

Finchilescu, G. (2010). Intergroup anxiety in interracial interaction: The role of prejudice and metastereotypes. Journal of Social Issues, 66(2), 334-351.

Fiske, S. T. (1993). Controlling other people: The impact of power on stereotyping. American Psychologist, 48(6), 621-628. 
Fiske, S. T., Cuddy, A. J., Glick, P., \& Xu, J. (2002). A model of (often mixed) stereotype content: Competence and warmth respectively follow from perceived status and competition. Journal of Personality and Social Psychology, 82(6), 878-902.

Fiske, S. T., \& Dépret, E. (1996). Control, interdependence and power: Understanding social cognition in its social context. European Review of Social Psychology, 7, 31-61. Chichester: Wiley.

Fiske, S. T., Lin, M., \& Neuberg, S. L. (1999). The continuum model: Ten years later. In S. Chaiken \& Y. Trope (Eds.), Dual-process theories in social psychology (pp. 231-254). New York, NY, US: Guilford Press.

Fiske, S. T., \& von Hendy, H. M. (1992). Personality feedback and situational norms can control stereotyping processes. Journal of Personality and Social Psychology, 62(4), 577-596.

Fryberg, S. A., Markus, H. R., Oyserman, D., \& Stone, J. M. (2008). Of warrior chiefs and Indian princesses: The psychological consequences of American Indian mascots. Basic and Applied Social Psychology, 30(3), 208-218.

Gawronski, B., \& Payne, B. K. (Eds.). (2010). Handbook of implicit social cognition: Measurement, theory, and applications. New York, NY US: Guilford Press.

Gilbert, D. T., \& Hixon, J. G. (1991). The trouble of thinking: Activation and application of stereotypic beliefs. Journal of Personality and Social Psychology, 60(4), 509-517.

Goodwin, S. A., Gubin, A., Fiske, S. T., \& Yzerbyt, V. Y. (2000). Power can bias impression processes: Stereotyping subordinates by default and by design. Group Processes \& Intergroup Relations, 3(3), 227-256.

Govorun, O., Fuegen, K., \& Payne, B. K. (2006). Stereotypes focus defensive projection. Personality and Social Psychology Bulletin, 32(6), 781-793.

Greenwald, A. G., McGhee, D. E., \& Schwartz, J. L. K. (1998). Measuring individual differences in implicit cognition: The implicit association test. Journal of Personality and Social Psychology, 74(6), 1464-1480.

Hamilton, D. L., Sherman, S. J., Crump, S. A., \& Spencer-Rodgers, J. (2009). The role of entitativity in stereotyping: Processes and parameters. In T. D. Nelson (Ed.), Handbook of prejudice, stereotyping, and discrimination (pp. 179-198). New York, NY US:

Psychology Press.

Hamilton, D. L., \& Trolier, T. K. (1986). Stereotypes and stereotyping: An overview of the cognitive approach. In J. F. Dovidio \& S. L. Gaertner (Eds.), Prejudice, discrimination, and racism (pp. 127-163). San Diego, CA US: Academic Press.

Haslam, S. A., Oakes, P. J., McGarty, C., Turner, J. C., Reynolds, K. J., \& Eggins, R. A. (1996). Stereotyping and social influence: The mediation of stereotype applicability and sharedness by the views of in-group and out-group members. British Journal of Social Psychology, 35(3), 369-397.

Hewstone, M., \& Brown, R. (1986). Contact is not enough: An intergroup perspective on the "contact hypothesis". In M. Hewstone \& R. Brown (Eds.), Contact and conflict in intergroup encounters (pp. 1-44). London, UK: Blackwell. 
Hewstone, M., Rubin, M., \& Willis, H. (2002). Intergroup bias. Annual Review of Psychology, 53(1), 575-604.

Hornsey, M. J., \& Hogg, M. A. (2000). Assimilation and diversity: An integrative model of subgroup relations. Personality and Social Psychology Review, 4(2), 143-156.

Huynh, Q.-L., Devos, T., \& Smalarz, L. (2011). Perpetual foreigner in one's own land: Potential implications for identity and psychological adjustment. Journal of Social and Clinical Psychology, 30(2), 133-162.

Jamieson, D. W., \& Zanna, M. P. (1989). Need for structure in attitude formation and expression. In A. R. Pratkanis, S. J. Breckler \& A. G. Greenwald (Eds.), Attitude structure and function. (pp. 383-406). Hillsdale, NJ England: Lawrence Erlbaum Associates, Inc.

Jost, J. T., Banaji, M. R., \& Nosek, B. A. (2004). A decade of system justification theory: Accumulated evidence of conscious and unconscious bolstering of the Status Quo. Political Psychology, 25(6), 881-920.

Judd, C. M., Park, B., Ryan, C. S., Brauer, M., \& Kraus, S. (1995). Stereotypes and ethnocentrism: Diverging interethnic perceptions of African American and White American youth. Journal of Personality and Social Psychology, 69(3), 460-481.

Jussim, L., Cain, T. R., Crawford, J. T., Harber, K., \& Cohen, F. (2009). The unbearable accuracy of stereotypes. In T. D. Nelson (Ed.), Handbook of prejudice, stereotyping, and discrimination (pp. 199-227). New York, NY US: Psychology Press.

Katz, D., \& Braly, K. (1933). Racial stereotypes of one hundred college students. The Journal of Abnormal and Social Psychology, 28(3), 280-290.

Klein, O., \& Snyder, M. (2003). Stereotypes and behavioral confirmation: From interpersonal to intergroup perspectives. Advances in Experimental Social Psychology, 35, 153-234.

Kruglanski, A. W., \& Webster, D. M. (1996). Motivated closing of the mind: 'Seizing' and 'freezing.' Psychological Review, 103(2), 263-283.

Lee, T. L., \& Fiske, S. T. (2006). Not an outgroup, not yet an ingroup: Immigrants in the stereotype content model. International Journal of Intercultural Relations, 30(6), 751768.

Lerner, J. S., \& Keltner, D. (2000). Beyond valence: Toward a model of emotion-specific influences on judgement and choice. Cognition and Emotion, 14(4), 473-493.

Leyens, J.-P., \& Demoulin, S. (2010). Ethnocentrism and group realities. In J. F. Dovidio, M. Hewstone, P. Glick \& V. M. Esses (Eds.), The SAGE handbook of prejudice, stereotyping, and discrimination (pp. 194-208). London, UK: Sage.

Lippman, W. (1922). Public opinion. New York, NY US: Harcourt \& Brace.

Livingston, R. W. (2002). The role of perceived negativity in the moderation of African Americans' implicit and explicit racial attitudes. Journal of Experimental Social Psychology, 38(4), 405-413.

Livingston, R. W., \& Brewer, M. B. (2002). What are we really priming? Cue-based versus category-based processing of facial stimuli. Journal of Personality and Social Psychology, 82(1), 5-18. 
Mackie, D. M., \& Hamilton, D. L. (Eds.). (1993). Affect, cognition and stereotyping: Interactive processes in group perception. San Diego, CA: Academic Press.

Mackie, D. M., Queller, S., Stroessner, S. J., \& Hamilton, D. L. (1996). Making stereotypes better or worse: Multiple roles for positive affect in group impressions. In R. M. Sorrentino \& E. T. Higgins (Eds.), Handbook of motivation and cognition (Vol. 3, pp. 371-396). New York, NY US: Guilford Press.

Mackie, D. M., \& Smith, E. R. (Eds.). (2002). From prejudice to intergroup emotions: Differentiated reactions to social groups. Philadelphia, PA: Psychology Press.

Macrae, C. N., \& Bodenhausen, G. V. (2000). Social cognition: Thinking categorically about others. Annual Review of Psychology, 51, 93-120.

Macrae, C. N., Bodenhausen, G. V., Milne, A. B., \& Jetten, J. (1994). Out of mind but back in sight: Stereotypes on the rebound. Journal of Personality and Social Psychology, 67(5), 808-817.

Macrae, C. N., Bodenhausen, G. V., Milne, A. B., Thorn, T. M. J., \& Castelli, L. (1997). On the activation of social stereotypes: The moderating role of processing objectives. Journal of Experimental Social Psychology, 33(5), 471-489.

Maddox, K. B., \& Dukes, K. N. (2008). Social categorization and beyond: How facial features impact social judgment. In N. Ambady \& J. Skowronski (Eds.), First impressions (pp. 205-233). New York, NY US: Guilford Press.

Monteith, M. J., Sherman, J. W., \& Devine, P. G. (1998). Suppression as a stereotype control strategy. Personality and Social Psychology Review, 2(1), 63-82.

Morrison, K. R., Plaut, V. C., \& Ybarra, O. (2010). Predicting whether multiculturalism positively or negatively influences white Americans' intergroup attitudes: The role of ethnic identification. Personality and Social Psychology Bulletin, 36(12), 1648-1661.

Mullen, B., Brown, R., \& Smith, C. (1992). Ingroup bias as a function of salience, relevance, and status: An integration. European Journal of Social Psychology, 22, 103-122.

Mummendey, A., \& Wenzel, M. (1999). Social discrimination and tolerance in intergroup relations: Reactions to intergroup difference. Personality and Social Psychology Review, $3(2), 158-174$.

Neuberg, S. L., \& Cottrell, C. A. (2006). Evolutionary bases of prejudices. In M. Schaller, J. A. Simpson \& D. T. Kenrick (Eds.), Evolution and social psychology (pp. 163-187). Madison, CT US: Psychosocial Press.

Neuberg, S. L., \& Fiske, S. T. (1987). Motivational influences on impression formation: Outcome dependency, accuracy-driven attention, and individuating processes. Journal of Personality and Social Psychology, 53(3), 431-444.

Norton, M. I., Sommers, S. R., Apfelbaum, E. P., Pura, N., \& Ariely, D. (2006). Color blindness and interracial interaction: Playing the political correctness game. Psychological Science, 17(11), 949-953.

Nosek, B. A., Smyth, F. L., Hansen, J. J., Devos, T., Lindner, N. M., Ranganath, K. A., Smith, C. T., Olson, K. R., Chugh, D., Greenwald, A. G., \& Banaji, M. R. (2007). Pervasiveness 
and correlates of implicit attitudes and stereotypes. European Review of Social Psychology, 18, 36-88.

Otten, S., \& Moskowitz, G. B. (2000). Evidence for implicit evaluative in-group bias: Affectbiased spontaneous trait inference in a minimal group paradigm. Journal of Experimental Social Psychology, 36(1), 77-89.

Overbeck, J. R., \& Park, B. (2001). When power does not corrupt: Superior individuation processes among powerful perceivers. Journal of Personality and Social Psychology, 81(4), 549-565.

Paladino, M.-P., \& Vaes, J. (2009). Ours is human: On the pervasiveness of infra-humanization in intergroup relations. British Journal of Social Psychology, 48(2), 237-251.

Park, B., \& Judd, C. M. (2005). Rethinking the link between categorization and prejudice within the social cognition perspective. Personality and Social Psychology Review, 9(2), 108130.

Peery, D., \& Bodenhausen, G. V. (2008). Black + White = Black: Hypodescent in reflexive categorization of racially ambiguous faces. Psychological Science, 19(10), 973-977.

Plaut, V. C., Garnett, F. G., Buffardi, L. E., \& Sanchez-Burks, J. (2011). "What about me?" Perceptions of exclusion and whites' reactions to multiculturalism. Journal of Personality and Social Psychology, 101(2), 337-353.

Pratto, F., \& Glasford, D. E. (2008). Ethnocentrism and the value of a human life. Journal of Personality and Social Psychology, 95(6), 1411-1428.

Purdie-Vaughns, V., Steele, C. M., Davies, P. G., Ditlmann, R., \& Crosby, J. R. (2008). Social identity contingencies: How diversity cues signal threat or safety for African Americans in mainstream institutions. Journal of Personality and Social Psychology, 94(4), 615-630.

Quinn, K. A., \& Macrae, C. N. (2005). Categorizing others: The dynamics of person construal. Journal of Personality and Social Psychology, 88(3), 467-479.

Richards, Z., \& Hewstone, M. (2001). Subtyping and subgrouping: Processes for the prevention and promotion of stereotype change. Personality and Social Psychology Review, 5(1), 5273.

Richeson, J. A., \& Nussbaum, R. J. (2004). The impact of multiculturalism versus colorblindness on racial bias. Journal of Experimental Social Psychology, 40(3), 417-423.

Richeson, J. A., \& Trawalter, S. (2005). Why do interracial interactions impair executive function? A resource depletion account. Journal of Personality and Social Psychology, 88(6), 934-947.

Riek, B. M., Mania, E. W., \& Gaertner, S. L. (2006). Intergroup threat and outgroup attitudes: A meta-analytic review. Personality and Social Psychology Review, 10(4), 336-353.

Rudman, L. A., Feinberg, J., \& Fairchild, K. (2002). Minority members' implicit attitudes: Automatic ingroup bias as a function of group status. Social Cognition, 20(4), 294-320.

Rutland, A., Cameron, L., Milne, A., \& McGeorge, P. (2005). Social norms and selfpresentation: Children's implicit and explicit intergroup attitudes. Child Development, 76(2), 451-466. 
Ryan, C. S., Hunt, J. S., Weible, J. A., Peterson, C. R., \& Casas, J. F. (2007). Multicultural and colorblind ideology, stereotypes, and ethnocentrism among Black and White Americans. Group Processes \& Intergroup Relations, 10(4), 617-637.

Schaller, M., Conway, L. G., III., \& Peavy, K. M. (2010). Evolutionary processes. In J. F. Dovidio, M. Hewstone, P. Glick \& V. M. Esses (Eds.), The SAGE handbook of prejudice, stereotyping, and discrimination (pp. 81-96). London, UK: Sage.

Schaller, M., Conway, L. G., III, \& Tanchuk, T. L. (2002). Selective pressures on the once and future contents of ethnic stereotypes: Effects of the communicability of traits. Journal of Personality and Social Psychology, 82(6), 861-877.

Schaller, M., Faulkner, J., Park, J. H., Neuberg, S. L., \& Kenrick, D. T. (2004). Impressions of danger influence impressions of people: An evolutionary perspective on individual and collective cognition. Journal of Cultural and Evolutionary Psychology, 2(3), 231-247.

Schwarz, N., \& Clore, G. L. (2003). Mood as information: 20 years later. Psychological Inquiry, 14(3-4), 296-303.

Sechrist, G. B., \& Stangor, C. (2001). Perceived consensus influences intergroup behavior and stereotype accessibility. Journal of Personality and Social Psychology, 80(4), 645-654.

Sherif, M., Harvey, O. J., White, B. J., Hood, W. R., \& Sherif, C. W. (1954). Intergroup conflict and cooperation: the Robbers Cave experiment. Norman: University of Oklahoma Book Exchange.

Sidanius, J., \& Pratto, F. (1999). Social dominance: An intergroup theory of social hierarchy and oppression. Cambridge, MA: Cambridge University Press.

Sinclair, L., \& Kunda, Z. (1999). Reactions to a Black professional: Motivated inhibition and activation of conflicting stereotypes. Journal of Personality and Social Psychology, 77(5), 885-904.

Spencer, S. J., Fein, S., Wolfe, C. T., Fong, C., \& Dunn, M. A. (1998). Automatic activation of stereotypes: The role of self-image threat. Personality and Social Psychology Bulletin, 24(11), 1139-1152.

Spencer-Rodgers, J., Hamilton, D. L., \& Sherman, S. J. (2007). The central role of entitativity in stereotypes of social categories and task groups. Journal of Personality and Social Psychology, 92(3), 369-388.

Stephan, W. G., \& Renfro, C. L. (2002). The role of threat in intergroup relations. In D. M. Mackie \& E. R. Smith (Eds.), From prejudice to intergroup emotions: Differentiated reactions to social groups (pp. 191-207). Philadelphia, PA: Psychology Press.

Stephan, W. G., \& Stephan, C. W. (1985). Intergroup anxiety. Journal of Social Issues, 41(3), 157-175.

Stroessner, S. J., \& Mackie, D. M. (1992). The impact of induced affect on the perception of variability in social groups. Personality and Social Psychology Bulletin, 18, 546-554.

Tajfel, H. (1981). Human groups and social categories: Studies in social psychology. Cambridge, UK: Cambridge University Press.

Tajfel, H., Billig, M. G., Bundy, R. P., \& Flament, C. (1971). Social categorization and intergroup behaviour. European Journal of Social Psychology, 1, 149-178. 
Trimble, J. E. (1988). Stereotypic images, American Indians and prejudice. In P. Katz \& D. Taylor (Eds.), Toward the elimination of racism: Profiles in controversy (pp. 181-202). New York, NY: Pergamon.

Trope, Y., \& Liberman, A. (1996). Social hypothesis testing: Cognitive and motivational mechanisms. In E. T. Higgins \& A. W. Kruglanski (Eds.), Social psychology: Handbook of basic principles. (pp. 239-270). New York, NY US: Guilford Press.

Trope, Y., \& Thompson, E. P. (1997). Looking for truth in all the wrong places? Asymmetric search of individuating information about stereotyped group members. Journal of Personality and Social Psychology, 73(2), 229-241.

Vallone, R. P., Ross, L., \& Lepper, M. R. (1985). The hostile media phenomenon: Biased perception and perceptions of media bias in coverage of the Beirut massacre. Journal of Personality and Social Psychology, 49(3), 577-585.

van Knippenberg, A., Dijksterhuis, A., \& Vermeulen, D. (1999). Judgement and memory of a criminal act: The effects of stereotypes and cognitive load. European Journal of Social Psychology, 29(2-3), 191-201.

Vescio, T. K., Gervais, S. J., Heidenreich, S., \& Snyder, M. (2006). The effects of prejudice level and social influence strategy on powerful people's responding to racial out-group members. European Journal of Social Psychology, 36(4), 435-450.

Waldzus, S., Mummendey, A., Wenzel, M., \& Boettcher, F. (2004). Of bikers, teachers and Germans: Groups' diverging views about their prototypicality. British Journal of Social Psychology, 43(Pt 3), 385-400.

Waldzus, S., Mummendey, A., Wenzel, M., \& Weber, U. (2003). Towards tolerance: Representations of superordinate categories and perceived ingroup prototypicality. Journal of Experimental Social Psychology, 39(1), 31-47.

Weary, G., Jacobson, J. A., Edwards, J. A., \& Tobin, S. J. (2001). Chronic and temporarily activated causal uncertainty beliefs and stereotype usage. Journal of Personality and Social Psychology, 81(2), 206-219.

Wenzel, M., Mummendey, A., \& Waldzus, S. (2007). Superordinate identities and intergroup conflict: The ingroup projection model. European Review of Social Psychology, 18, 331372.

Wheeler, M. E., \& Fiske, S. T. (2005). Controlling racial prejudice: Social-cognitive goals affect amygdala and stereotype activation. Psychological Science, 16(1), 56-63.

Wigboldus, D., \& Douglas, K. (2007). Language, stereotypes, and intergroup relations. In K. Fiedler (Ed.), Social communication. (pp. 79-106). New York, NY US: Psychology Press.

Wigboldus, D. H. J., Semin, G. R., \& Spears, R. (2000). How do we communicate stereotypes? Linguistic bases and inferential consequences. Journal of Personality and Social Psychology, 78(1), 5-18.

Wittenbrink, B., \& Schwarz, N. (2007). Implicit measures of attitudes. New York, NY US: Guilford Press. 
Wolsko, C., Park, B., \& Judd, C. M. (2006). Considering the tower of Babel: Correlates of assimilation and multiculturalism among ethnic minority and majority groups in the United States. Social Justice Research, 19(3), 277-306.

Wolsko, C., Park, B., Judd, C. M., \& Wittenbrink, B. (2000). Framing interethnic ideology: Effects of multicultural and color-blind perspectives on judgments of groups and individuals. Journal of Personality and Social Psychology, 78(4), 635-654.

Wyer, N. A., Sherman, J. W., \& Stroessner, S. J. (1998). The spontaneous suppression of racial stereotypes. Social Cognition, 16(3), 340-352.

Yzerbyt, V. Y. (2010). Motivational processes. In J. F. Dovidio, M. Hewstone, P. Glick \& V. M. Esses (Eds.), The SAGE handbook of prejudice, stereotyping, and discrimination (pp. 146-162). London, UK: Sage.

Zárate, M. A., \& Shaw, M. P. (2010). The role of cultural inertia in reactions to immigration on the U.S./Mexico border. Journal of Social Issues, 66(1), 45-57. 